\title{
Tipping into the abyss: with more than a virtual parachute?
}

\author{
Chris Tompsett* \\ Kingston University, UK
}

\begin{abstract}
Any application of information and communication technology in education (ICTE) sits, at times uncomfortably, at the intersection of three key disciplines: technology, education and sociology (including reflexivity). To confuse matters, any specific study may need to take account of specific knowledge within subdisciplines, such as organisational management and technology transfer, and of knowledge within the domain of application (e.g. nursing, social work, fashion, etc.). Researchers must build a consistent model of knowledge that can integrate disparate methodologies, research goals and even conflicting interpretations of the same terminology. Without this, the ICTE research field will be dominated by what is simply novel, irrespective of the relevance of particular changes to educational practice. If existing models in this field are as limited as suggested by Moule, when should lecturers and teachers, with no motivation to use technology for its own sake and no additional financial support, review progress in this field for effective examples of innovative practice, let alone wide-scale change? On most of the criteria that could be introduced to compare two papers, the views of Moule and Salmon appear almost diametrically opposed and a detailed comparison would seem of limited value. Instead, this paper asks a more fundamental question: what could be the basis within this research community for establishing coherence within the field and ensuring that research can justify actual changes in educational practice?
\end{abstract}

\section{Introduction}

Providing a critical analysis of research literature that lies between the views of Moule (2006, 2007a, b) and Salmon (2000, 2007) would demand far more space than this brief commentary will allow, but, as the intention is to foster debate and discussion, it makes more sense for detailed consideration of individual aspects to be considered by later contributors. The present article, instead, is intended to suggest that a number of critical factors must be considered in any subsequent discussion to ensure that the debate fosters developments in this field towards the establishment of reliable outcomes for educational practitioners to adopt (cf. Hargreaves, 1996), rather than experimental or innovative, practice (Rogers, 1962). Questions will be examined

\footnotetext{
*Kingston University, Learning Technology Research Group, Penrhyn Road, Kingston upon Thames, London KT1 2EE, UK. Email: cptompsett@king.ac.uk
} 
necessarily in turn, within the dialogical format of this paper, but that oversimplifies the underlying theme. Questions regarding the construction of knowledge itself are inherently circular: the processes of research and education are implicitly entwined with the nature of knowledge and how it can be learned. Some further issues can only be raised; in relation to these, pointers are given towards more detailed discussions that exist elsewhere. The intention is therefore to create a 'playground' within which colleagues can discuss these two papers, always allowing, if need be, for others to remodel the playground itself.

\section{Remember education?}

The rate of technical development in information and communication technology produces an ephemeral research agenda in ICTE. Complex and critical research questions are raised with one particular technology but disappear as researchers gain funding to test new ideas without resolving the issues that limit the potential value of previous work to educational practice. The current interest in m-learning, for example, either acts as a replacement for wired technology (a technical rather than educational problem) or else reduces the emphasis on visual attention, when full-size screens and existing interface devices remain hopelessly inadequate in many subjects. While such work is necessary in the first stages of development, the constant changes in the research agenda leave much started and little complete. Even where research in ICTE works specifically within an educational environment, and suggests that educational improvement has been achieved, it is far too common for 'improvements' to be attributed to the technological change rather than the many other educational changes that may also have taken place. These improvements are, of course, invalidated, if the measures of improvement themselves are different from those already used (MacFarlane, 2004). If there was little disparity between this community's conception of ICTE, and that of those in education, there would be little need for MacFarlane's suggestion that all research teams should include both educators and technologists.

This disparity is emphasised when distinctions that would be understood in education become lost within this research community. When juxtaposed with instructivism, constructivism appears as a coherent position but, when applied within education, it hides a multiplicity of meanings. Laurillard (2004), for example, suggests 13 different models of constructivist education. Some interpretations may provide subtle distinctions, or reflect a change in context, but other differences entail a radically different model of knowledge, learning and education and the interrelationship between these concepts. Laurillard's selection would not cover the full set covered in ICTE, let alone education. Activity theory (Engeström, 1991; Engeström et al., 1999) would need to be included, as it is a key socio-constructivist position that remains distinct from but complementary to the views of Vygotsky, Lave and Wenger (see Lave \& Wenger, 1991, p. 31). Similarly, Chomsky would need to be added to complement the views of Piaget and Papert (see Piattelli-Palmarini, 1980).

Researchers in ICTE might also benefit from a number of systematic reviews and meta-studies that have been published more extensively within the education field. 
The benefits of peer-group discussion and networked learning are clearly difficult to establish (for example, Andrews et al., 2002; Goldberg et al., 2003; Hogarth et al., 2005). A careful analysis of these reviews/studies provides interesting examples of what not to repeat, what is required to establish educational benefits and to provide benchmarks for the standard of research that can be achieved.

\section{Why sociology?}

For those who are striving to integrate the most recent innovations in ICTE, such as podcasts and the semantic web, it may also seem unusual to insist that due attention is given to sociological issues in research. However, the reasons to do so increase from year to year. For the educationalist, 'blended learning' and 'work-based learning' blur the self-evident separation (for those in educational practice) that students are either studying, working or 'not studying' (i.e. living). For the technologists, the increasing focus on delivering solutions through technology to the new generation of technologically aware 'screenagers' (Watson, 2006, p. 10) depends on understanding the sociological function of such technology. The interest that each student may show in self-selected web-logs or the individual collection of performances that are stored on an MP3 player may well be remarkable, but there is no socio-cultural justification that the same interest will transfer when the freedom to choose content is removed and/or dictated by some other agent. Even if the same enthusiasm were to be transferable, researchers seem unwilling to discuss the inherent limitations that restrict the quality and range of content when compared with alternative modes of interaction and delivery (with or without technology). At the very least, a socio-technical approach (Checkland \& Scholes, 1991) is required to understand the way in which each group of users (educators, support staff and students) are likely to react unless 'required' to do so. In the latter case, an even wider research framework is needed to understand how such 'requirements' may be legitimated or flouted (see, for example, Latour, 1992).

Selecting an appropriate critical framework for sociological modelling may seem arbitrary, when first encountered, since some of the most critical terms, such as 'community', are defined in contradictory ways. In exchange theory (and also action research), the characteristics of a community must be determined by the choices made by each of the individuals. In a functionalist model, a community may acquire independent characteristics above and beyond those that follow from its members. If we include socio-constructivist models, whether Vygotskian, activity theoretical or communities of practice (respectively Wertsch, 1985; Engeström, 1991; Wenger, 1998), then the primary focus on the individual over the community is reversed. Wenger (1998), for example, only addresses individuality after five chapters on practice. Each of these models determines the objects that can be observed within the world, their potential properties and the possible relationships between them. These then determine how knowledge is established and shared, the relevance of existing research to the current problem and, from this, the extent to which any results from this project may be relevant to future projects. If 'communication' is only researched in terms of 
communication within a discussion group but cannot capture informal discussions and conversations, then the researchers will be blind to interactions that could be far more significant in educational terms (for example, Steyn \& Cronje, 2006). If the behaviour of scientists 'in the laboratory' is observed to the same level of detailed analysis as other cultural groups, it becomes clear that social controls and unscientific arguments are as common and entrenched as in any other hierarchical professional group. The post$h o c$, rationalised descriptions that are published in scientific journals simply report what a scientist is allowed to report (Latour \& Woolgar, 1986).

As some critical terminology (e.g. community, constructivist) has markedly different connotations depending on the approach chosen, it is incumbent on those reporting the research to ensure that these differences are presented coherently within the published literature. Failing to do so can, in extreme cases, lead to terms becoming meaningless; for example, with the concept of the DELPHI methodology in decision support (Dalkey \& Helmer, 1963; Linstone \& Turoff, 1975; Hasson et al., 2000; Mitroff \& Turoff, 2002). Avoiding this problem requires that there is consistency between the problem, model and methodology within the research - and clarity of reporting for the relevant readership. A pick-and-mix approach, or lack of awareness of the issues that need to be managed within almost all of the approaches, opens the suggestion that such research is unaware of the critical issues that affect learning within a technological society.

\section{Reflexivity}

Although there is insufficient room to review all of the wide range of issues that are considered within a properly conducted sociological study, one particular issue cannot be ignored-since it is introduced as soon as a study expects to account for any factor that influences human behaviour beyond the purely clinical. If a researcher believes that some set of properties, personal or social, affects how subjects report, learn and reflect new learning in their behaviours or interactions with others, then the same range of factors could influence the researcher(s) themselves-the principle of reflexivity (Ashmore, 1989). At the simplest level this requires that the researcher is aware of, and accounts for, their own influence on the research processes (reflective self-awareness-the researcher as a non-independent observer; Ashmore, 1989, p. 32). At a more fundamental level (and frequently missed in most such studies), it is generally unsound to conduct research in which the relationship between actions, learning and knowledge that is expected to apply to any subjects is distinct from that applied to researchers themselves (reflective self-reference; p. 32). Merrill et al. (1996) proposed a laboratory study comparing individual with group-based learning, but failed to note that some aspects of group inter-activity might be lost when informal interactions were transferred to artificial environments and scheduled times so that they could be 'observed'. Alsop and Tompsett (2006) provide a more detailed analysis of this issue in the case of phenomenography.

In ICTE, as well as in education, additional levels of inconsistency may be introduced between knowledge in the domain, models of assessment and models of learning 
(Wenger, 1998, epilogue) — and even between course design and models of student learning. Dirckinck-Holmfeld et al. (2004) provide one of the few cases within the community of practice model in which consistency has been achieved. In contrast, Zuber-Skerrit (1992) provides some cases within the action research model where course designers clearly apply one model to themselves and a different one to their students. Some contradictions may be unavoidable, but that does not remove the need to recognise that they exist and to address them within the research process.

\section{Conclusions}

The differences in perspective, approach and scope of the work of Gilly Salmon and Pam Moule cover a considerable range of viewpoints regarding the nature of research in this field, and there is a risk that a continuing discussion might result in revealing differences within the community that are interesting from the 'intellectualist' position (Oancea, 2005) but that are of little value to those engaged in educational practice. For those in educational practice, even if research progresses beyond the simply technological, innovative work is seldom pursued to the point at which effectiveness is sufficiently proven to justify a change in practice (Alsop \& Tompsett, 2007). These two opposing views provide an opportunity to discuss and reassess the future of research in this field. If there are to be rules for the debate, then this author would argue strongly that the aims and principles of education and sociology need to become embedded as centrally as technology is at present. Without that, research in this community will become increasingly self-focused, leading to improvements in a virtual reality that are incapable of influencing educational practice in a real world.

\section{References}

Alsop, G. \& Tompsett, C. (2006) Making sense of 'pure' phenomenography in information and communication technology in education, ALT-f, 14(3), 241-259.

Alsop, G. \& Tompsett, C. (2007) From effect to effectiveness: the missing research questions, Education, Technology and Society, 10(1), 28-39.

Andrews, R., Burn, A., Leach, J., Locke, T., Low, G. \& Torgerson, C. (2002) A systematic review of the impact of networked ICT on 5-16 year olds' literacy in English (London, EPPI-Centre, Social Science Research Unit, Institute of Education).

Ashmore, M. (1989) The reflexivity thesis: wrighting sociology of scientific knowledge (Chicago, IL, The Chicago University Press).

Checkland, P. \& Scholes, J. (1991) Soft systems methodology in action (Chichester, John Wiley and Sons).

Dalkey, N. \& Helmer, O. (1963) An experimental application of the Delphi method to the use of experts, Management Science, 9(3), 458-467.

Dirckinck-Holmfeld, L., Sorensen, E. K., Ryberg, T. \& Buus, L. (2004) A theoretical framework for designing online master communities of practice. Networked Learning 2004 (Lancaster, Lancaster University).

Engeström, Y. (1991) Activity theory and individual and social transformation, Multi-disciplinary Newsletter for Activity Theory, 7/8, 6-17.

Engeström, Y., Miettinen, R. \& Punamäki, R.-L. (1999) Perspectives on activity theory (Cambridge, Cambridge University Press). 
Goldberg, A., Russel, M. \& Cook, A. (2003) The effect of computers on student writing: a metaanalysis of studies from 1992 to 2002, The fournal of Technology, Learning and Assessment, 1. Available online at: http://http://www.jtla.org (accessed 12 April 2007).

Hargreaves, D. H. (1996) Teaching as a research-based profession: possibilities and prospects (London, Teacher Training Agency).

Hasson, F., Keeney, S. \& McKenna, H. (2000) Research guidelines for the Delphi survey technique, fournal of Advanced Nursing, 32(4), 1008-1015.

Hogarth, S., Bennett, J., Campbell, B., Lubben, F. \& Robinson, A. (2005) A systematic review of the use of small-group discussions in science teaching with students aged 11-18, and the effect of different stimuli (print materials, practical work, ICT, videolfilm) on students' understanding of evidence. Research evidence in education library (London, EPPI-Centre, Social Science Research Unit, Institute of Education).

Latour, B. (1992) Where are the missing masses? The sociology of a few mundane artifacts, in: W. Bijker \& J. Law (Eds) Shaping technology/building society: studies in sociotechnical change (Cambridge, MA, MIT Press), 225-258.

Latour, B. \& Woolgar, S. (1986) Laboratory life: the construction of scientific facts (Princeton, NJ, Princeton Paperbacks).

Laurillard, D. (2004) Realising the vision for e-learning (London, BETT).

Lave, J. \& Wenger, E. (1991) Situated learning: legitimate peripheral participation (Cambridge, Cambridge University Press).

Linstone, H. A. \& Turoff, M. (Eds) (1975) The Delphi method: techniques and applications (Reading, MA, Addison Wesley Inc.).

MacFarlane, A. (2004) E-pedagogy—conference review, paper presented at $A L T-C$ 2004, Exeter, UK.

Merrill, D. M., Drake, L., Lacy, M. J. \& Pratt, J. (1996) Reclaiming instructional design, Educational Technology, 36(5), 5-7.

Mitroff, I. I. \& Turoff, M. (2002) IIB. Philosophical and methodological foundations of Delphi, in: H. A. Linstone \& M. Turoff (Eds) The Delphi method: techniques and applications (New Jersey Institute of Technology). Available online at: http://is.njit.edu/pubs/delphibook/ (accessed 29 March 2007).

Moule, P. (2006) E-learning for healthcare students: developing the communities of practice framework, Fournal of Advanced Nursing, 54(3), 370-380.

Moule, P. (2007a) Challenging the five-stage model for e-learning: a new approach, $A L T-\mathcal{f}, 15(1)$, $37-50$.

Moule, P. (2007b) The tipping point-a response, $A L T-f$, 15(2), 173-174.

Oancea, A. (2005) Criticisms of educational research: key topics and levels of analysis, British Educational Research fournal, 31(2), 157-183.

Piattelli-Palmarini, M. (Ed.) (1980) Language and learning: the debate between fean Piaget and Noam Chomsky (Cambridge, MA, Harvard University Press).

Rogers, E. M. (1962) Diffusion of innovations (New York, The Free Press).

Salmon, G. (2000) E-moderating: the key to teaching and learning online (London, Kogan Page).

Salmon, G. (2007) The tipping point, ALT-f, 15(2), 171-172.

Steyn, D. \& Cronje, J. (2006) Interpreting cross-cultural blended teaching and learning along Hofstede's cultural dimensions, paper presented at e/merge 2006: learning landscapes in Southern Africa Online Conference. Available online at: http://emerge2006.net (accessed 1 March 2007).

Watson, D. (2006) Whatever happened to the student experience?, Academy Exchange, 4(Summer), 9-11.

Wenger, E. (1998) Communities of practice: learning, meaning and identity (Cambridge, Cambridge University Press).

Wertsch, J. V. (1985) Vygotsky and the social formation of the mind (London, Harvard University Press).

Zuber-Skerrit, O. (1992) Professional development in higher education-a theoretical framework for action research (London, Kogan Page). 